ERRATUM

Christy A. Beal • Douglas W. Tallamy

\title{
A new record of amphisexual care in an insect with exclusive paternal care: Rhynocoris tristis (Heteroptera: Reduviidae)
}

Published online: June 24, 2006

J Ethol DOI 10.1007/s10164-005-0190-2

The article cited above should have appeared as a Short communication, not as an Article. 